УДК 621.315 .592

\title{
Исследование влияния легирования железом на люминесценцию монокристаллов селенида цинка
}

\author{
(C) А.А. Гладилин ${ }^{1}$, Н.Н. Ильичев ${ }^{1}$, В.П. Калинушкин ${ }^{1}$, М.И. Студеникин ${ }^{1}$, \\ О.В. Уваров ${ }^{1}$, В.А. Чапнин ${ }^{1}$, В.В. Туморин ${ }^{1}$, Г.Г. Новиков ${ }^{2}$ \\ ${ }^{1}$ Институт общей фризики им. А.М. Прохорова Российской академии наук, \\ 119991 Москва, Россия \\ ${ }^{2}$ Национальный исследовательский ядерный университет „МИФИ“, \\ 115409 Москва, Россия \\ E-mail: agladilin@kapella.gpi.ru
}

(Получена 15 января 2018 г. Принята к печати 19 января 2018 г.)

Исследовано влияние легирования железом (термодиффузия с поверхности) на люминесценцию монокристаллов селенида цинка в диапазоне длин волн 0.44-0.72 мкм и пространственное распределение центров люминесценции. Методом двухфотонной конфокальной микроскопии получены „плоские“ и „объемные“ карты краевой (экситонной) и примесно-дефектной люминесценции в указанном выше спектральном диапазоне, как в легированных, так и в нелегированных кристаллах. Показано, что области кристалла с высокой концентрацией железа имеют низкую интенсивность люминесценции в этом диапазоне. Обнаружено, что в процессе диффузии образуется несколько типов примесно-дефектных центров, распределение которых в объеме кристаллов носит сложный характер. Обсуждается природа этих центров.

DOI: 10.21883/FTP.2019.01.46979.8821

\section{1. Введение}

Кристаллы ZnSe, легированные железом, используются в качестве активных сред при разработке твердотельных лазеров среднего инфракрасного (ИК) диапазона (3-5 мкм) [1]. В последнее время достигнуты рекордные

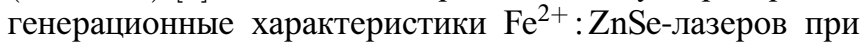
оптической накачке ионов железа Er:YAG-лазером и газоразрядными лазерами на фториде водорода [1-5]. Однако создание малогабаритной высокоэффективной лазерной системы с использованием в качестве источника накачки известных лазеров среднего ИК диапазона в настоящее время мало вероятно. В последние годы идет поиск других путей создания инверсной населенности уровней $\mathrm{Fe}^{2+}$ - в частности за счет их ударной ионизации „горячими“ (с энергией несколько кэВ) электронами или использования для этих целей лазеров, работающих в видимом или ближнем ИК диапазоне [6,7]. Это требует детального изучения примесно-дефектной структуры кристаллов $\mathrm{Fe}^{2+}: \mathrm{ZnSe}$. Работы в этом направлении необходимы и для усовершенствования технологии получения материалов и лазерных элементов высокого качества на их основе. Использование двухфотонной конфокальной микроскопии позволит выявлять характер изменения примесно-дефектного состава матрицы $\mathrm{ZnSe}$ на всех стадиях изготовления лазерного материала, сохраняя целостность заготовки. Эта методика дает возможность регистрировать спектры люминесценции не только в приповерхностном слое, но и в объеме исследуемого образца, снимать „плоские“ и „объемные“ карты люминесценции. Это позволяет соотносить пространственное распределение центров люминесценции образца с концентрационным профилем легирующего элемента и изучать примесно-дефектный состав непосредствен- но в рабочей зоне кристаллов. Использование техники и математического обеспечения конфокальных микроскопов позволяет за несколько минут получать объемные карты краевой и примесно-дефектной люминесценции до глубин $\sim 1$ мм с пространственным разрешением в несколько мкм и осуществлять обработку массивов полученной информации [8]. В [9] сообщалось об исследовании примесно-дефектного состава нелегированного и легированного железом и хромом получаемого методом CVD (chemical vapor deposition) поликристаллического $\mathrm{ZnSe}$ (в дальнейшем CVD-ZnSe) с помощью двухфотонной конфокальной микроскопии. В данной работе представлены первые результаты использования двухфотонной конфокальной микроскопии для исследования пространственного распределения собственных и связанных с фоновыми примесями точечных дефектов и их комплексов в исходных (специально не легированных) и легированных железом с поверхности методом термодиффузии в образцах монокристаллического $\mathrm{ZnSe}$, выращенных из газовой фазы.

\section{2. Экспериментальная часть}

Для исследований были отобраны следующие образцы.

- Образцы типа 1: образцы высокочистого монокристаллического $\mathrm{ZnSe}$, использованные для легирования железом. Методика выращивания этих кристаллов приведена в $[10,11]$. В статье такие образцы обозначаются как исходные.

- Образцы типа 2: монокристаллы ZnSe, легированные железом методом термодиффузии с поверхности при температуре $850^{\circ} \mathrm{C}$ в течение 216 ч в атмосфере аргона. 
- Образцы типа 3: монокристаллы $\mathrm{ZnSe}$, легированные железом методом термодиффузии с поверхности при температуре $1000^{\circ} \mathrm{C}$ в течение 168 ч в атмосфере водорода.

Для исследования спектров фотолюминесценции (ФЛ) при комнатной температуре использовались конфокальный микроскоп фирмы Carl Zeiss LSM 710 NLO. Двухфотонное возбуждение осуществлялось лазером с перестраиваемой длиной волны в диапазоне 0.71-1.05 мкм (как правило, использовалось излучение с длиной волны 0.8 мкм). Длительность импульса составляла 150 фс, частота - 80 МГц, максимальная средняя мощность варьировалась в пределах $0.1-1$ Вт в зависимости от условий детектирования и оптимизировалась для получения контрастного изображения люминесценции образца. Спектры люминесценции регистрировались в диапазоне длин волн $\lambda=440-725$ нм со спектральным разрешением 10 нм. Эти параметры хорошо подходят для исследования кристаллического $\mathrm{ZnSe}$, ширина запрещенной зоны которого составляет при комнатной температуре $\sim 2.7$ эВ. Таким образом, на этом приборе возможна эффективная реализация двухфотонного возбуждения, регистрация краевой и части примесно-дефектной люминесценции в диапазоне длин волн 460-715 нм.

Использовалась стандартная схема эксперимента: излучение возбуждающего лазера фокусировалось в определенную область кристалла и проводилось сканирование по плоскости. При этом регистрировалась люминесценция области, в которой происходит генерация носителей, с разложением по спектру. В результате получался набор „плоских“ карт люминесценции с определенной длиной волны области кристалла, имеющей форму, близкую к прямоугольному параллелепипеду с квадратным основанием со стороной $\sim 1$ мм и высотой несколько мкм. Затем проводилась перефокусировка излучения лазера на другую глубину. Таким образом, снимался набор „Плоских“ карт на разных расстояниях от поверхности. В результате формировалась „объемная“ карта люминесценции, состоящая из наборов „плоских“ карт, расположенных на разных расстояниях от поверхности. Необходимо отметить, что нужно учитывать ослабление интенсивности люминесценции и мощности накачки за счет поглощения кристаллом. Нами снималось поглощение исследуемых в данной работе образцов в диапазоне 0.4-1 мкм. Однако очень большие значения коэффициента поглощения (сотни, тысячи $\mathrm{cm}^{-1}$ ) и сильная зависимость его от длины волны в области $0.46-0.5$ мкм и от степени легирования в области 0.5-1 мкм затрудняют использование этих данных для точного учета ослабления интенсивности люминесценции. Для решения этой задачи в работе использованы результаты измерения люминесценции с двух перпендикулярных плоскостей кристалла. Сравнение этих результатов позволяет исключить влияние поглощения на полученные результаты. Имеющееся экспериментальное оборудование позволяло регистрировать и обрабатывать трехмерные картины распреде- ления краевой и примесно-дефектной люминесценции исходных и легированных железом кристаллов $\mathrm{ZnSe}$ на глубину до 3 мм с пространственным разрешением порядка нескольких мкм. Время снятия одной объемной карты на глубину 1 мм с шагом 25 мкм и размером плоской площадки $1 \times 1$ мм составляло $\sim 5$ мин. Все эксперименты проводились при комнатной температуре.

Исследуемые образцы представляли собой пластины толщиной 1.7 мм. Легирование велось с обеих поверхностей кристалла размером $15 \times 10$ мм. Перед измерениями эти поверхности всех образцов механически полировались абразивным алмазным синтетическим порошком. Снимались „плоские“ и „объемные“ карты при облучении поверхности, с которой осуществлялось легирование (в дальнейшем - плоские и объемные карты). В данной работе также исследовалась люминесценция со сколов этих кристаллов, сделанных перпендикулярно плоскости легирования (в дальнейшем - плоские и объемные карты со сколов). В этих измерениях концентрация железа изменялась вдоль поверхности скола. Такая схема экспериментов позволяла исключить влияние поглощения люминесценции и излучения накачки на результаты. Снимая на одной глубине плоскую карту по сколу, имеем зависимость распределения интенсивности люминесценции от расстояния от поверхности легирования, на которую не влияют указанные выше факторы. Эта техника позволила получить новые интересные результаты по распределению центров люминесценции в легированных методом термодиффузии железа кристаллах селенида цинка.

Сколы образцов делались методом скрайбирования поверхности пластины с одной стороны и последующим раскалыванием, так что на противоположной скрайбированной стороне скола, как правило, формировался не поврежденный край. Качество поверхности сколов контролировалось с помощью конфокальной микроскопии и сканирующей электронной микроскопии в режиме вторичных электронов. Поверхность скола представляла собой фрагментарно плоскую поверхность с отдельными террасами.

\section{3. Результаты и обсуждение}

На рис. 1 приведены типичные спектры люминесценции нелегированного $\mathrm{ZnSe}$. В них можно выделить следующие группы полос: интенсивная полоса излучения в диапазоне 460-480 нм (в дальнейшем „синяя“ полоса); широкая полоса от 500 до $\sim 700$ нм с максимумом в районе 560 нм и пологим спадом до 700 нм (в дальнейшем „зеленая“ полоса), причем форма этой полосы немного меняется в разных областях исследуемых кристаллов; слабые по интенсивности полосы в области 680 и 720 нм (в дальнейшем „красные“ полосы).

Аналогичные спектры наблюдались ранее и при исследовании CVD-ZnSe [9], однако „зеленая“ и „красные“ 


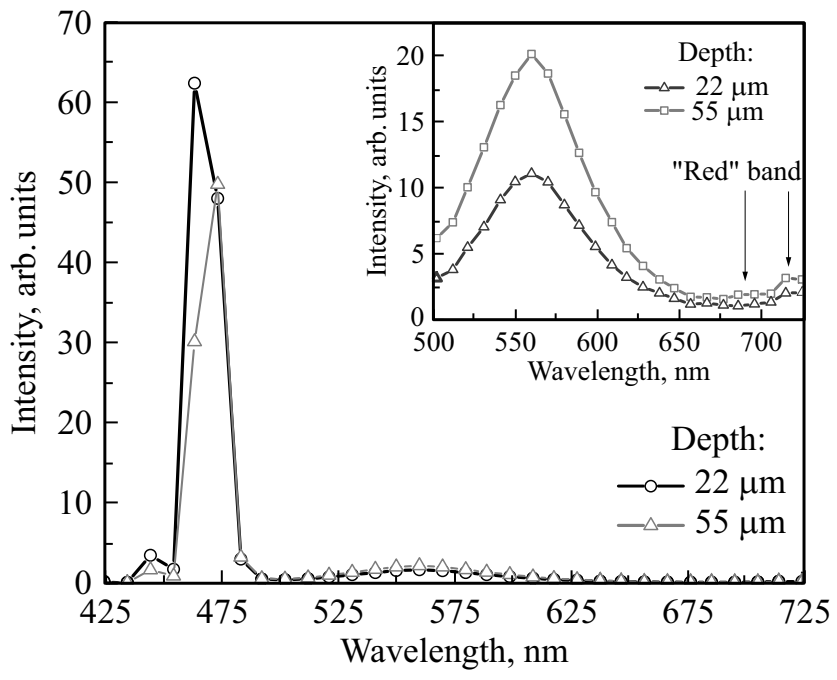

Рис. 1. Спектры ФЛ нелегированного кристалла ZnSe на разных расстояниях от поверхности в диапазоне длин волн 425-725 нм. На вставке - „зеленая“ и „красная“ полосы в спектре ФЛ нелегированного кристалла ZnSe на разном расстоянии от поверхности в спектральном диапазоне $500-725 \mathrm{HM}$.

полосы надежно выявлялись только в образцах, легированных железом и хромом.

При исследовании пространственного распределения люминесценции со стороны механически полированной поверхности было обнаружено, что область, близкая к ней, имеет низкую интенсивность „синей“, „зеленой“ и „красной“ полос люминесценции. При увеличении расстояния от поверхности до 10-15 мкм наблюдается резкий рост интенсивности люминесценции этих полос. В дальнейшем происходит быстрый спад интенсивности коротковолновой области „синей“ полосы (с длиной волны $463 \mathrm{нм).} \mathrm{Область} \mathrm{„синей“} \mathrm{полосы} \mathrm{с} \mathrm{большей}$ длиной волны спадает существенно медленнее, и она начинает доминировать в спектре (см. вставку на рис. 1). Однако на глубинах $\sim 100$ мкм „синяя“ полоса исчезает. Интенсивность „зеленой“ и „красной“ полос также растет при удалении от поверхности. В дальнейшем интенсивности этих полос слабо меняются до глубин $\sim 300$ мкм. При больших расстояниях они также начинают уменьшаться. Аналогичные результаты наблюдались ранее при исследовании CVD-ZnSe [9]. Однако они нуждаются, как отмечалось выше, в корректировке ввиду необходимости учета поглощения излучения люминесценции и мощности оптической накачки. Особенно это существенно для диапазона 450-480 нм, где поглощение $\mathrm{ZnSe}$ велико. В этом диапазоне лежит край собственного поглощения $\mathrm{ZnSe}$, где значение коэффициента поглощения может достигать тысяч см$^{-1}$ и резко (на порядки) меняется в этом диапазоне при небольшом изменении длины волны. Поэтому интенсивность излучения с длиной волны 463 нм существенно сильнее уменышается при исследовании областей, расположенных достаточно далеко от поверхности образца, чем интенсивность длинноволнового излучения (с длиной волны $473 \mathrm{Hм}$ ). Влияние поглощения должно быть менее существенным при регистрации люминесценции с бо́льшими длинами волн. Однако при исследовании областей кристалла, расположенных далеко от поверхности, и оно может быть заметно, в том числе вследствие поглощения излучения оптической накачки. Для корректировки распределения интенсивности люминесценции по глубине кристалла люминесценция исследовалась на сколе кристалла. На рис. 2 приведены плоская карта люминесценции, снятая на длине волны 541 нм, и зависимости интенсивности люминесценции с длиной волны 463, 541 и 715 нм
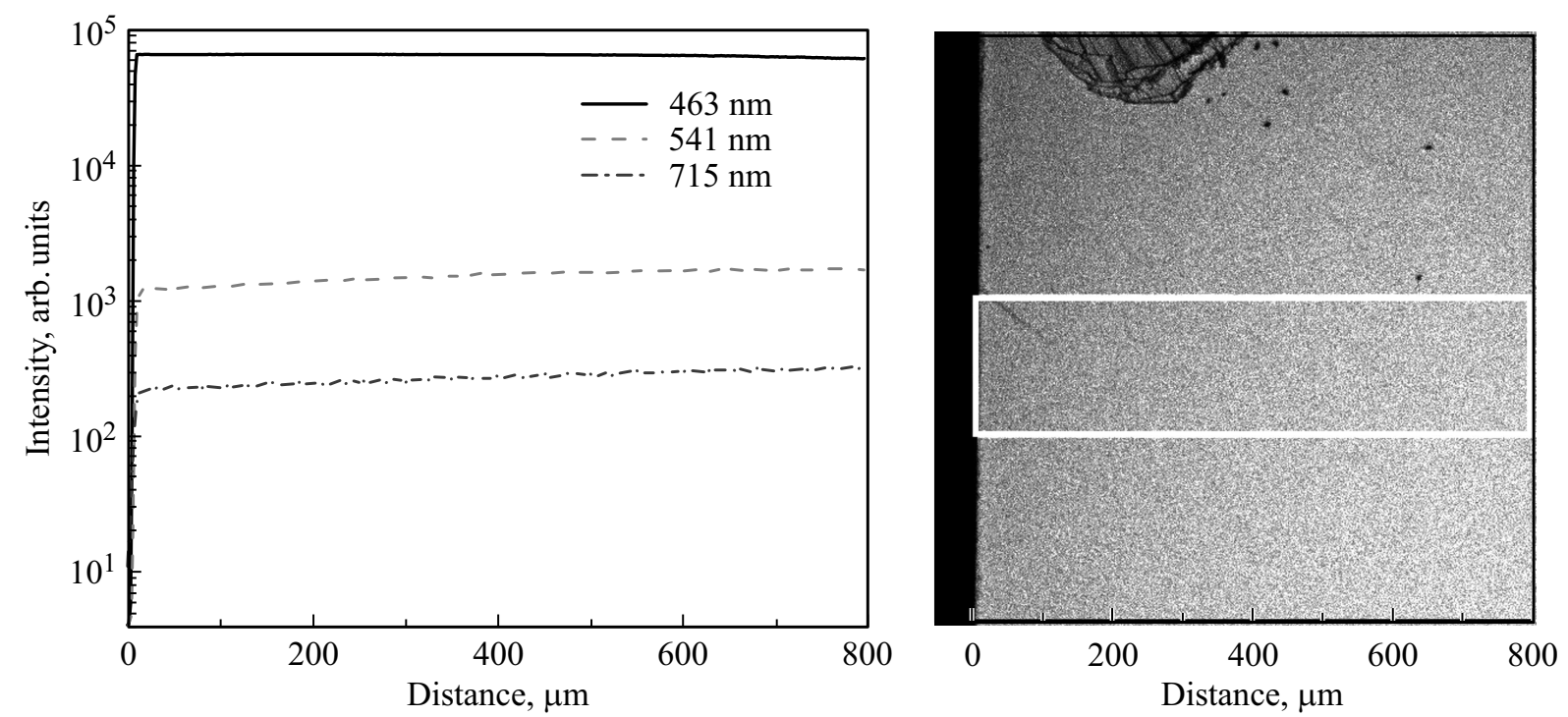

Рис. 2. Пространственное распределение ФЛ нелегированного кристалла $\mathrm{ZnSe}$ в глубь образца от поверхности и плоская карта ФЛ со скола на длине волны 541 нм (выделенная область — область обработки данных). 


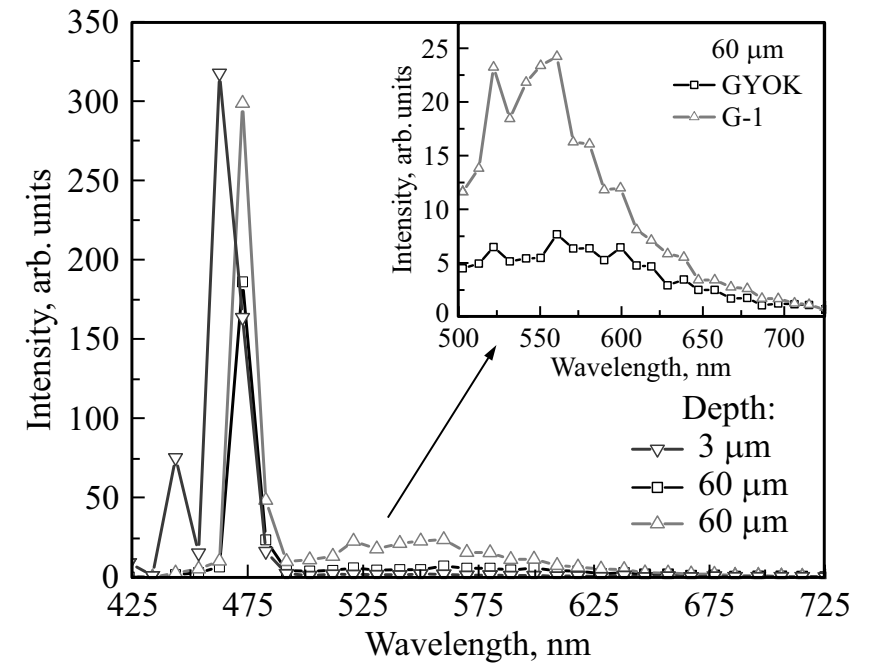

Рис. 3. Спектр ФЛ кристалла $\mathrm{ZnSe}: \mathrm{Fe}$ (тип 2) на разных расстояниях от поверхности легирования и в разных пространственных позициях на одной глубине. На вставке - „ЗЖОК“ (GYOK) и „зеленая-1“ (G-1) полосы спектра в разных областях на глубине 60 мкм.

от расстояния от механически полированной поверхности из выделенного на рисунке прямоугольника, снятые на глубине 40 мкм от поверхности скола. Видно, что интенсивность „синей“, „зеленой“ и „красных“ полос минимальна вблизи механически полированной поверхности. Затем она быстро нарастает, а в дальнейшем практически не зависит от расстояния. Эти результаты типичны для нелегированных кристаллов $\mathrm{ZnSe}$ типа 1, исследованных в данной работе.

При исследовании люминесценции с плоскости скола область малой интенсивности люминесценции, аналогичная наблюдаемой при исследовании с механически полированной поверхности, отсутствует. Однако наблюдается увеличение интенсивности ,зеленой“ и „красных“ полос в 2-3 раза при перемещении зоны измерения люминесценции в глубину образца (см. вставку на рис. 1).

Легирование железом приводит к изменениям спектров люминесценции и к образованию в кристаллах $\mathrm{ZnSe}$ областей с различными люминесцентными характеристиками. Спектр люминесценции кристаллов типа 2 на рис. 3 состоит из „синей“ полосы $(460-480$ нм), двух линий в районе ,зеленой“ полосы (500-700 нм) и нескольких слабых по интенсивности линий в диапазоне „красной“ полосы $(680-720$ нм). Эти полосы частично перекрываются и, хотя они различаются по форме, надежно разделить их возможно благодаря тому, что их интенсивности различны в различных областях кристаллов. Форма „синей“ полосы, а также зависимость ее интенсивности и формы от расстояния от поверхности кристалла совпадают с наблюдаемыми результатами при исследовании нелегированных материалов (рис. 1, 3). Одна из полос в диапазоне 500-700 нм близка к наблюдаемой в нелегированных кристаллах „зеленой“ полосе - более крутой рост интенсивности в коротковолновой области и пологий спад в длинноволновой области (см. вставку на рис. 3). В дальнейшем называем ее „зеленая-1“ полоса. Другая полоса в этом диапазоне имеет спектр в виде пологого спада от 500 до как минимум 700 нм без четкого максимума (см. вставку на рис. 3). В дальнейшем обозначим ее как „зелено-желто-оранжево-красная“ („ЗЖОК ${ }^{\text {‘ }}$ ) полоса. Полоса в диапазоне 680-720 нм, как и в нелегированных материалах, имеет малую интенсивность и о ее форме говорить сложно (см. вставку на рис. 3). Возможно, она является хвостом „зеленой-1“ полосы. В дальнейшем будем называть ее „красная-1“ полоса. Пространственное распределение интенсивности всех этих полос в кристалле $\mathrm{ZnSe}$ носит сложный характер. На рис. 4 приведена плоская карта люминесценции со скола на длине волны 560 нм, снятая на расстоянии 60 мкм от поверхности скола кристалла, сделанного перпендикулярно поверхности легирования. Из выделенного на плоской карте прямоугольника получены зависимости интенсивности люминесценции на длинах волн 473, 541, 686 и 725 нм. Результаты типичны для образцов типа 2. В этих кристаллах можно выделить следующие характерные области: зона I c высокой концентрацией железа; область II, прилегающая к зоне I; область III с низкой концентрацией железа. В области III в спектрах доминируют „синяя“ полоса в диапазоне длин волн 460-480 нм и „ЗЖОК“ полоса в диапазоне длин волн 500-700нм (рис. 3, 4). Как и при исследовании CVD-ZnSe, в области I (высоких концентраций железа) наблюдается, так называемая „мертвая зона“ - область с низкой интенсивностью люминесценции в исследуемом диапазоне. В отличие от приповерхностной зоны с малой интенсивностью люминесценции с размерами в несколько мкм в нелегированных кристаллах, размеры мертвой зоны в легированных образцах достигают сотен мкм. По мере удаления от поверхности интенсивность люминесценции всех полос растет. Рост интенсивности аппроксимировался экспонентами. Результаты аппроксимации приведены в табл. 1. К области I примыкает область II, которая характеризуется высокой интенсивностью „зеленой-1“

Таблица 1. Показатели экспоненциальной функции, аппроксимирующей распределения люминесценции в образце типа 2 на различных длинах волн

\begin{tabular}{c|c|c}
\hline Длина волны, нм & Расстояние, мкм & Показатель экспоненты \\
\hline \multirow{2}{*}{473} & $1-46$ & 0.089 \\
& $46-104$ & 0.057 \\
\hline 541 & $39-112$ & 0.065 \\
\hline \multirow{2}{*}{686} & $58-110$ & 0.048 \\
& $54-84$ & 0.027 \\
& $79-110$ & 0.062 \\
\hline 725 & $81-121$ & 0.038
\end{tabular}




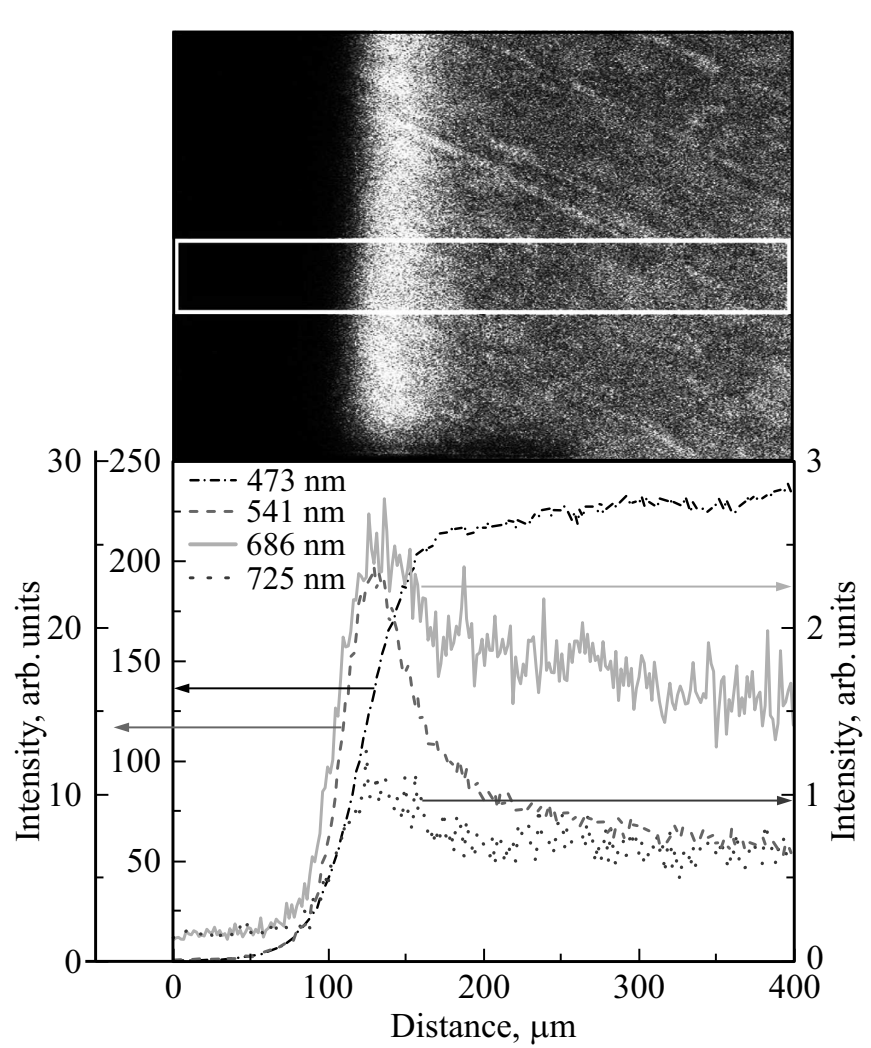

Рис. 4. Пространственное распределение ФЛ кристаллов $\mathrm{ZnSe}: \mathrm{Fe}$ (тип 2) от поверхности легирования в глубь кристалла на разных длинах волн и плоская карта распределения ФЛ на длине волны 560 нм с выделенной областью, в которой получено распределение.

„красной-1“ полос (рис. 4). Как отмечалось выше, эти полосы перекрываются по спектру с „ЗЖОК“ полосой, и надежно разделить их стало возможным благодаря тому, что они доминируют в разных областях кристалла.

В спектре люминесценции области III доминирует излучение „синей“ и „ЗЖОК““ полос (рис. 4). Возможно, в этой области есть люминесценция „красной-1“ полосы, однако ее малая интенсивность в этой зоне кристалла не позволяет надежно отличить ее от возможного „хвоста“ „ЗЖОК“ полосы.

Эти результаты согласуются с данными, полученными при исследовании люминесценции с поверхности кристалла, с которой велось легирование железом: наблюдается малая интенсивность в области, прилегающей к поверхности, с которой велось легирование, и имеющей высокую концентрацию железа. В дальнейшем интенсивность люминесценции растет и выходит на плато. Область II выявляется повышенной интенсивностью люминесценции „зеленой-1“ полосы. Однако необходимость учета поглощения делает более предпочтительными результаты экспериментов, проводимых со стороны скола.

Исследование люминесценции легированных железом образцов типа 3 приводит к аналогичным результатам. В спектре излучения наблюдаются (рис. 5): „си- няя“ полоса; широкая полоса с максимумом в районе 540 нм и пологим спадом в длинноволновую область „зеленая-2“ полоса; линии в районе 680-720нм „красная-2“ полоса. Поведение „синей“ полосы аналогично описанному выше. Полосы в длинноволновой области спектра похожи на наблюдаемые в нелегированных кристаллах. Несколько сдвинут максимум „зеленой-2“ полосы в коротковолновую область по отношению к ,зеленой“ полосе в нелегированных образцах и ,зеленой-1“ полосе в образцах типа 1. Спектр „красной- $2^{“}$ полосы из-за малой интенсивности зарегистрирован с низкой точностью, и сравнивать его со спектрами других типов образцов сложно. Коренное различие люминесценции образцов типа 3 и нелегированных образцов - в пространственном распределении интенсивности люминесценции. Как и в случае образцов типа 2, в кристаллах типа 3 в результате легирования железом образуются области с разными люминесцентными характеристиками. Плоская карта люминесценции со скола образца типа 3 на длине волны 541 нм и зависимости интенсивности люминесценции из выделенного на карте прямоугольника на длинах волн 473, 541 и 715 нм, снятые на расстоянии 60 мкм от поверхности скола, перпендикулярного к поверхности легирования, приведены на рис. 6. Эти результаты типичны для образцов типа 3. В этих кристаллах можно выделить следующие области: I - область с повышенной концентрацией железа; II область насыщения „синей“ и „зеленой“ полос (выходят на плато); III - область между I и II, в которой интенсивность люминесценции „красной“ полосы возрастает. Как и в случае образцов типа 2 область I характеризуется малой интенсивностью люминесценции „синей“ и „зеленой-2“ полос. При этом размер области I для кристаллов типа 3 существенно больше, чем в случае кристаллов типа 2. Возможно, происходит перекрытие

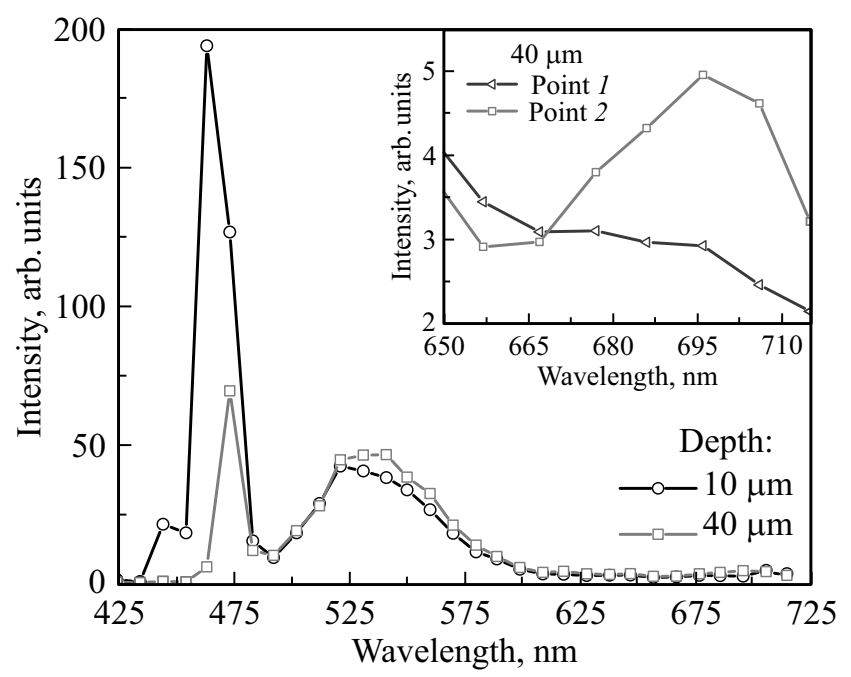

Рис. 5. Спектры ФЛ кристаллов $\mathrm{ZnSe}: \mathrm{Fe}$ (тип 3) на разном расстоянии от поверхности легирования. На вставке - спектр ФЛ в диапазоне 650-725 нм в разных областях кристалла на глубине 40 мкм. 


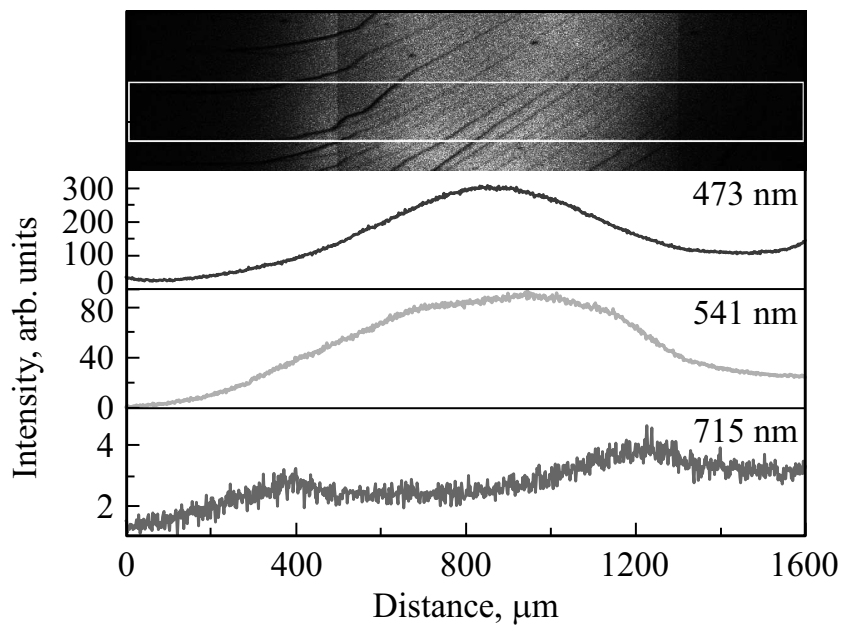

Рис. 6. Пространственное распределение ФЛ в кристалле $\mathrm{ZnSe}: \mathrm{Fe}$ (тип 3) на разных длинах волн и плоская карта распределения ФЛ на длине волны 541 нм с выделенной областью, в которой получено распределение

областей I в результате двухстороннего легирования образцов типа 3. Кривые роста интенсивности люминесценции наблюдаемых полос аппроксимировались экспонентами. Результаты аппроксимации приведены в табл. 2. Видно, что показатели экспонент для образцов типа 3 меньше, чем для образцов типа $2-0.001-0.002$ и $0.025-0.03$ соответственно (табл. 1,2 ). Также из табл. 2 следует, что интенсивность ,зеленой-2“ полосы растет быстрее (показатель экспоненты 0.004), чем „синей“ полосы. В результате область II в кристаллах типа 3, возможно, состоит из двух частей. В спектре люминесценции этой области доминирует люминесценция „синей“ и „зеленой-2“ полос. Однако, как видно из рис. 6, интенсивность люминесценции ,зеленой-2“ полосы выходит на плато на расстоянии $\sim 700$ мкм от поверхности легирования. Интенсивность люминесценции „синей“ полосы либо вообще не выходит на плато, либо это происходит при расстояниях от поверхности, с которой шло легирование, 900 мкм.

На рис. 6 также приведено пространственное распределение интенсивности люминесценции „красной-2“ по-

Таблица 2. Показатели экспоненциальной функции, аппроксимирующей распределения люминесценции в образце типа 3 на различных длинах волн

\begin{tabular}{c|c|c|c|c}
\hline $\begin{array}{c}\text { Длина } \\
\text { волны, нм }\end{array}$ & $\begin{array}{c}\text { Pасстояние, } \\
\text { мкм }\end{array}$ & $\begin{array}{c}\text { Показатель } \\
\text { экспоненты }\end{array}$ & $\begin{array}{c}\text { Расстояние, } \\
\text { мкм }\end{array}$ & $\begin{array}{l}\text { Показатель } \\
\text { экспоненты }\end{array}$ \\
\hline \multirow{2}{*}{473} & $99-526$ & 0.00418 & $1055-1338$ & 0.0028 \\
& - & - & $1318-1467$ & 0.000585 \\
\hline \multirow{2}{*}{541} & $46-308$ & 0.00999 & $1149-1303$ & 0.00404 \\
& - & - & $1313-1454$ & 0.0022 \\
\hline 715 & $36-396$ & 0.00211 & - & -
\end{tabular}

лосы с максимумом при 715 нм. Эта полоса наблюдается в образцах типа 3 и имеет максимум интенсивности в области II - примерно в середине „мертвой“ зоны.

Полученные результаты позволяют утверждать следующее.

- Наблюдаемая в исходных кристаллах $\mathrm{ZnSe}$ в области 460-480 нм люминесценция обусловлена связанными на различных примесях и дефектах экситонами [12]. По-видимому, наблюдаются две различные линии, с длинами волн 462 и 473 нм, соответствующие связанным на разных примесях экситонам. Уменьшение интенсивности этих линий при исследовании областей кристаллов, расположенных на больших расстояниях от поверхности, обусловлено с их сильным поглощением объемом кристалла.

— „Зеленая“ полоса, скорее всего, связана с люминесценцией примесно-дефектных комплексов. В [9] отмечалось, что это могут быть комплексы собственных точечных дефектов $\left(\mathrm{Zn}_{i}, V_{\mathrm{Zn}}\right)$ с кислородом и другими фоновыми примесями. Как сообщалось в [13], эти комплексы могут иметь несколько модификаций (разные расстояния между элементами комплексов), что приводит к вариации энергетических уровней. Этим можно объяснить большую ширину зеленой полосы и изменения ее формы при исследовании люминесценции из разных небольших объемов кристалла. В разных относительно небольших областях кристалла могут быть различные концентрации комплексов различных типов. Это может приводить к изменениям в форме спектра. При регистрации люминесценции из большего объема происходит усреднение, что приводит к формированию широкой полосы.

- „Красная“ полоса обусловлена, скорее всего, так же примесно-дефектными комплексами, но по своей природе они, по-видимому, отличаются от комплексов, обеспечивающих люминесценцию „зеленой“ полосы. Отсутствие ,зеленой“ и „красной“ полос в нелегированных кристаллах, исследованных ранее в [9], скорее всего, связано с более высокой чистотой и более высокой стехиометричностью этих материалов по сравнению с исследуемыми в данной работе. Также не исключено, что, поскольку в [9] исследовались поликристаллические образцы, границы зерен могли быть стоками для указанных выше примесно-дефектных комплексов.

- Распределение интенсивности люминесценции „синей“ и „зеленой“ полос в макроскопическом масштабе достаточно однородно, за исключением областей, примыкающих к механически полированной поверхности. Это соответствует принятым представлениям: образование нарушенного слоя при механической полировке должно приводить к резкому уменьшению времени жизни носителей заряда и спаду как краевой, так и других видов люминесценции.

- Легирование железом приводит к определенным изменениям в спектрах и существенным изменениям в пространственном распределении люминесцентных характеристик. В спектрах легированных образцов, как 
и в случае нелегированных кристаллов, наблюдается излучение связанных экситонов („синяя“ полоса). Одновременно наблюдается ряд линий в области длин волн $>500$ нм, имеющих разную интенсивность в различных областях кристаллов.

- Образование областей I в кристаллах типов 2 и 3 с низкой интенсивностью полос излучения экситонов и всех полос кроме „красной-2“ связано с процессом диффузии железа. Больший размер этих областей и меньшая крутизна нарастания интенсивности люминесценции в образцах типа 3 связаны с большей температурой легирования этих образцов и соответственно с большей скоростью диффузии железа. Эти части кристаллов имеют высокую концентрацию атомов железа и, возможно, различных других примесно-дефектных центров, которые могут образовываться в результате диффузии. Соответственно в этих областях рекомбинация носителей заряда может идти, например, через атомы железа или какие-либо вводимые в процессе диффузии дополнительные дефекты. Механизмы рекомбинации в этих случаях могут быть как безызлучательными, так и приводящими к люминесценции в других диапазонах длин волн. Факт гашения экситонной и примесно-дефектной люминесценции при легировании железом наблюдался и ранее [14-16]. Однако использование применяемой в данной работе методики позволило получить дополнительную информацию о природе этого эффекта. В частности, ясно, что одним из конкурирующих с атомами железа каналов рекомбинации носителей в области I являются дефекты, ответственные за обнаруженную в ней „красную-2“ полосу с максимумом в районе 715 нм. Профиль распределения в кристалле этой полосы свидетельствует о том, что это не атомы железа. Для более детального понимания механизмов гашения краевой и части примесно-дефектной люминесценции в областях с высокой концентрацией железа необходимо сопоставление профилей интенсивности люминесценции и концентрации железа. Сейчас это стало возможным благодаря двухфотонной конфокальной микроскопии и сканирующей фурье-спектроскопии.

- Центры, ответственные за появление ,зеленой-1“, „ЗЖОК“ и ,зеленой-2“ полос, скорее всего, являются примесно-дефектными центрами, не связанными напрямую с легирующей примесью. Полосы „зеленая-1“ и „зеленая- $2^{“}$ по форме похожи на наблюдаемую в нелегированных кристаллах „зеленую“ полосу и, возможно, имеют ту же природу. Смещение максимума люминесценции может быть связано с тем, что в процессе легирования меняется соотношение концентраций различных модификаций комплексов $\left(\mathrm{Zn}_{i}, V_{\mathrm{Zn}}\right)$, что может приводить к некоторым изменениям формы интегральной полосы люминесценции. В процессе термодиффузии железа образуется большое число собственных точечных дефектов и идут сложные процессы их диффузии, а также образования различных комплексов с их участием. По-видимому, это приводит к образованию локальной области с повышенной концентрацией этих дефектов непосредственно за областью легирования (область II в кристаллах типа 2 и часть области II в кристаллах типа 3). Механизм образования этих областей неясен. Его определение требует сопоставления профилей люминесценции, концентрации железа и поглощения в видимом диапазоне, появляющихся после термодиффузии.

- Область III в образцах типа 2 и вторая часть области II в образцах типа 3 представляют собой части кристаллов, где влияние атомов железа и образующихся в результате легирования дефектов не так велико. В них наблюдается интенсивная экситонная люминесценция, что свидетельствует об уменьшении концентрации конкурирующих центров люминесценции. В образцах типа 3 эту зону, возможно, не удается четко наблюдать из-за более высокой температуры легирования и соответственно больших размеров области I, которая занимает практически весь образец.

- Регистрируемая в кристаллах типа 2 широкая „ЗЖОК“ полоса может быть результатом загрязнения неконтролируемыми примесями образцов во время процесса легирования.

- Природа „красных“ полос неясна. Малая интенсивность их люминесценции затрудняет сравнение их спектральной формы. Пространственное распределение интенсивности люминесценции существенно различается для всех типов образцов. Возможно, природа их в разных типах образцов различна. Так, в образцах типа 3, возможно, за их появление ответственны центры, образующиеся непосредственно в процессе легирования. В исходных же образцах и в образцах типа 2 люминесценция „красных“ полос связана с центрами, ответственными за люминесценцию „зеленой“ и „зеленой-1“ полос.

\section{4. Заключение}

В люминесценции нелегированных кристаллов селенида цинка, выращенных при комнатной температуре, в диапазоне 0.44-0.48 мкм доминирует краевая люминесценция (связанные экситоны). Наблюдается также люминесценция на примесно-дефектных центрах с максимумами при 540, 690 и 720 нм.

Полоса люминесценции с максимумом при 540 нм, скорее всего, связана с комплексами собственных точечных дефектов $\left(\mathrm{Zn}_{i}, V_{\mathrm{Zn}}\right)$ с кислородом или другими фоновыми примесями и представляет собой комбинацию линий с близкими длинами волн. Природа центров, ответственных за люминесценцию в диапазоне 680 и 720 нм, неизвестна.

Люминесцентные характеристики нелегированных кристаллов достаточно однородны по объему исследуемых образцов.

Обнаружено, что легирование железом приводит к резкому увеличению неоднородности кристаллов $\mathrm{ZnSe}$. Показано, что в них образуются области с размерами в сотни мкм с существенно различными люминесцентными характеристиками, в ряде случаев не связанные 
с концентрационным профилем распределения железа. Возможно, это объясняет расхождение в получаемых для этих материалов результатах при возбуждении люминесценции светом с разными длинами волн [17].

Легирование железом с помощью термодиффузии приводит к появлению обширной зоны, в которой подавлена межзонная люминесценция. Рекомбинация неравновесных носителей заряда происходит в основном либо через атомы железа, либо через дефекты, вводимые в процессе термодиффузии.

Легирование приводит к образованию в кристалле $\mathrm{ZnSe}: \mathrm{Fe}$ областей с повышенной концентрацией новых примесно-дефектных центров с участием собственных дефектов $\mathrm{ZnSe}$, как вне пределов части кристалла с высокой концентрацией железа, так и внутри нее.

Работа подготовлена при поддержке программы президиума РАН № 7 „Актуальные вопросы фотоники, зондирование неоднородных сред и материалов“ и „Фундаментальные основы прорывных технологий двойного назначения в интересах национальной безопасности“ (проект „Исследование возможности создания высокоэффективных лазеров ИК диапазона (4-5 мкм) на основе кристаллов $\mathrm{ZnSe}$, легированных железом, при ударном возбуждении ионов активатора горячими электронами"6).

\section{Список литературы}

[1] S. Mirov, V. Fedorov, D. Martyshkin, I. Moskalev, M. Mirov, S. Vasilyev. IEEE J. Select. Top. Quant. Electron., 21 (1), 1 (2015).

[2] K.N. Firsov, E.M. Gavrishchuk, S.U. Kazantsev, I.G. Kononov, S.A. Rodin. Laser Phys. Lett., 11 (8), 085001 (2014).

[3] D.V. Martyshkin, D.V. Fedorov, M. Mirov, I. Moskalev, S. Vasilyev, S.B. Mirov. In: CLEO: OSA Technical Digest (2015) paper SF1F. 2.

[4] Е.М. Гаврищук, В.Б. Иконников, С.Ю. Казанцев, И.Г. Кононов, С.А. Родин, Д.В. Савин, Н.А. Тимофеева, К.Н. Фирсов. Квант. электроника, 45 (9), 823 (2015).

[5] Д.В. Савин, Е.М. Гаврищук, В.Б. Иконников, О.Н. Еремейкин, А.С. Егоров. Квант. электрон., 45 (1), 8 (2015).

[6] А.А. Гладилин, Е.С. Гулямова, В.П. Данилов, Н.Н. Ильичев, В.П. Калинушкин, И.Н. Один, П.П. Пашинин, Р.Р. Резванов, А.В. Сидорин, М.И. Студеникин, В.А. Чапнин, М.В. Чукичев. Квант. электрон., 46 (6), 545 (2016).

[7] J. Peppers, V.V. Fedorov, S.B. Mirov. Opt. Express, 23 (4), 4406 (2015).

[8] В.П. Калинушкин, О.В. Уваров. ЖТФ, 86 (12), 119 (2016).

[9] Е.М. Гаврищук, А.А. Гладилин, В.П. Данилов, В.Б. Иконников, Н.Н. Ильичев, В.П. Калинушкин, А.В. Рябова, М.И. Студеникин, Н.А. Тимофеева, О.В. Уваров, В.А. Чапнин. Неорг. матер., 52 (11), 1 (2016).

[10] Yu.V. Korostelin, V.I. Koslovsky, A.S. Nasibov, P.V. Shapkin. J. Cryst. Growth, 161, 651 (1966).

[11] Yu.V. Korostelin, V.I. Koslovsky, A.S. Nasibov, P.V. Shapkin. J. Cryst. Growth, 197, 449 (1999).

[12] Д.Д. Недеогло, А.В. Симашкевич. Электрические и люминесцентные свойства селенида иинка (Кишинев, Штиинца, 1984).
[13] F.S. Rong, W.A. Barry, J.F. Donegan, G.D. Watkins. Phys. Rev. B, 54 (11), 7779 (1996).

[14] L.L. Kulyuk, R. Laiho, A.V. Lashkul, E. Lahderanta, D.D. Nedeoglo, I.V. Radevici. Physica B, 405, 4330 (2010).

[15] M. Surma, M. Godlewski, T.R. Surkova. Phys. Rev. B, 50, 8319 (1994).

[16] M. Tabei, S. Shionoya, H. Ohmatsu. Jpn. J. Appl. Phys., 14, 240 (1975)

[17] Ю.Ф. Ваксман, Ю.А. Ницук, В.В. Яцун, А.С. Насибов, П.В. Шапкин. ФТП, 45 (9), 1171 (2011).

Редактор Л.В. Шаронова

\section{Investigation of iron doping influence on luminescence of single-crystal zinc selenide}

\author{
A.A. Gladilin ${ }^{1}$, N.N. Ilichev ${ }^{1}$, V.P. Kalinushkin ${ }^{1}$, \\ M.I. Studenikin ${ }^{1}$, O.V. Uvarov ${ }^{1}$, V.A. Chapnin ${ }^{1}$, \\ V.V. Tumorin ${ }^{1}$, G.G. Novikov ${ }^{2}$ \\ ${ }^{1}$ Prokhorov General Physics Institute, \\ Russian Academy of Sciences, \\ 119991 Moscow, Russia \\ ${ }^{2}$ National Research Nuclear University „MEPHI“, \\ 115409 Moscow, Russia
}

\begin{abstract}
The influence of iron doping (thermal diffusion from the surface) on the luminescence of zinc selenide single crystals in the wavelength range of $0.44-0.72 \mu \mathrm{m}$ and the spatial distribution of luminescence centers are studied. Two-photon confocal microscopy has been used to obtain „planar" and „volumetric“ maps of edge (exciton) and impurity-defect luminescence in the above spectral range of both doped and undoped crystals. It has been shown that regions of a crystal with high iron concentration have a low luminescence intensity in this range. It is found that during the thermal diffusion process several types of impurity-defect centers are formed, whose distribution in the bulk of the crystals is of a complex problem. The nature of these centers is discussed.
\end{abstract}

